operations for the relief or cure of naso-pharyngeal troubles in young children nowadays.

Harrogate, March 26th, 1910. I am, Sir, yours faithfully, T. JoHNSTONE.

\section{VARICOCELE AND THE PUBLIC SERVICES.}

To the Editor of THE LANCET.

SIR,-Having initiated the discussion on this subject in your columns in 1905, I am gratified to see you return to the charge in a second leading article. So strongly do I feel this heartless, needless, and useless mutilation of youths who are keen to serve in the army that $I$ consider it the bounden duty of the surgical profession to bring about a reform of the clause in the regulations recommending operation. I trust that all who may now discuss the subject will read carefully my letter of Sept. 23rd, 1905. One point bearing on the experience of other military surgeons than myself I then omitted to mention; it is this : I asked three of my colleagues employed in reeruiting at St. George's Barracks whether they had ever treated any officer or soldier for varicocele during their service, and I received a prompt reply in the negative. Now, here were four of us army surgeons with an aggregate of 120 years' service in different parts of the world, and yet not one of us had ever seen any inefficiency from varicocele. Is it, then, that varicocele is more prevalent now than it was in years gone by? If so, why is it? What is the per mille, or per ten mille, rate of the condition treated in civil hospitals? When I invited naval surgeons (who reject for varicocele in any form outright) to give us their experience few, if any, responded. I know not why, for a military medical officer is not prohibited from expressing a professional opinion on a disputed question. If there is grave risk with one in a thousand of these operations the War Office is not justified in recommending an operation.

The whole business is, in my opinion, a phantasm which I trust you will succeed in laying, and I further trust that you may receive aid from the Director-General of the Army Medical Staff in doing so. It has often occurred to me that I should like now to carry out a thorough examination of all the candidates who have had operations performed to discover what have been the results. Those I examined years ago did not assure me of success.

\section{I am, Sir, yours faithfully,}

Frank HowaRd, Colonel (retired), Army Medical Staff. Cromwell Mansions, S.w., March 26th, 1910.

\section{To the Editor of THE LAYCE'T.}

SIR, - On reading the article in THE LANCET, "Varicocele and the Public Services," I was reminded of a conversation I had with the late Sir James Paget some years ago on the question of operation for varicocele, when he informed me that Nelaton had told him that he had never seen a case of varicocele amongst all the soldiers that had passed through his hands at the Hôtel aes Invalides in Paris, which must have been a very considerable number. From this he argued that varicocele has a tendency to disappear in later life. Should this be borne out by other observers, is it not a strong argument in favour of not making the operation compulsory before entering the public services?

$$
\text { I am, Sir, yours faithfully, }
$$

York, March 26th, 1910. W. H. JALLAND.

\section{ACCIDENT CLAIMS AS AFFECTING THE MEDICAL PROFESSION.}

\section{To the Editor of THE LANCET.}

SIR, - I shall be obliged if you will allow me to place the following facts and opinions before your readers as $I$ feel sure that you will agree with me that the subject is most important, and although my opinions may be distasteful to a very small minority $I$ am certain that they will be endorsed by the great majority of the profession. Having during the last 15 years devoted my time almost entirely to the examination of cases of personal injury caused, or supposed to be caused, by accident, during which time I have examined over 11,000 cases, it will perhaps be granted that I must have had a large experience of the attitude shown by the profession when dealing with such cases.

Firstly, I wish to say that in that experience I have found medical men, with the exception of a very small percentage, absolutely straightforward and artious to do their duty impartially, having due regard to the interests of their patients who were actually suffering from the effects of accident and whose claims were bon $\hat{a}$ fide, and also having the same due regard to the interests of these claimed upon, if the disability was non-existent or greatly exaggerated. I am greatly pleased to bear witness to the upright attitude which has been in an enormous number of cases assumed by medical men who had immense inducements offered to them to diverge in some small degree from absolute honesty and truth. Many members of the profession will bear me out in voicing the difficulties continually encountered in dealing with claims.

1. Medical men in good practice have frequently rich patients - patients who are either valuable in themselves or by their connexions, patients whom they have always before thought to be eminently respectable and trustworthy, who, when face to face with an accident claim, seem to lose every particle of moral fibre. It may be that such a patient has an accident or an alleged accident, and some time after a doctor has been in attendance, during which time he has seen little or no objective sign of injury, it is suddenly sprung upon him that there is an accident claim pending, of which he has heard nothing and which at the last moment throws light on an obscure and bewildering case. A medical man called in to a patient is obliged to treat the aches and pains that are complained of, for if there are no objective signs he cannot discredit his patient and refuse to attend him; in fact, he would be very wrong in so doing, as there are many traumatisms of which there is no visible objective sign; but when he has treated his patient for some time with purely negative results as to the cause of the trouble complained of, what is he to do when suddenly asked to sign an accident claim certificate? He has to think, and the difficulties that confront him are immense, and if he is a struggling practitioner a source of insidious temptation.

2. Medical men associated with elubs are continually attacked by clever malingerers, so clever that they sometimes deceive the very elect ; these make various statements when there is no sign of injury, and the difficulty arises as to how far the patient is to be believed, especially as if he is not believed, the medical man will be most likely threatened with the loss of the club, even if the claim is palpably a bogus one. Medical men are, however, in this matter not on a pinnacle by themselves, as I find that solicitors to societies and legal assistance clubs have sometimes the greatest pressure brought to bear on them with similar threats.

3. Medical men acting for a certain class of employer and the smaller fry of insurance offices are frequently in a very difficult position, as they are sent to examine workmen, being told beforehand to expect an absolute malingerer, for there is a certain order of lay mind to which the slightest particle of truth is unknown and to whom it is most distasteful. 1 say without fear that the profession has, under this stress, in the past nobly done its duty and has only been degraded by a few black sheep who must be present in every large flock.

I wish to call, however, the attention of the readers of THE LANCE' to a development which has recently occurred, and which should, in my opinion, be nipped in the bud. Under the Workmen's Compensation Act, 1906, which largely extended the benefits of the previous Act, I regret to say that certain members of the profession, and some few even with high qualifications, are not acting up to the traditions of the profession and are bringing discredit on it, not only with employers and insurance offices, but with workmen and their organisations. As a Medical Referee appointed by the Home Secretary I have had many cases referred to me for report, in which the evidence shows that two medical men on each side have sworn diametrically opposite to one another on questions not of opinion but of perfectly apparent fact. I fully understand that medicine is not an exact science and there must be differences of opinion between the most high-minded men as to the condition or prognosis of certain cases, but I am reluctantly obliged to come to the conclusion that there are a few medical men now in London who will do everything possible for the person or persons by whom they 